\title{
The Quest for Quality Science Education Experiences in Tanzanian Secondary Schools
}

\author{
John Fungulupembe Kalolo (PhD) \\ Mkwawa University College of Education, Faculty of Education \\ Psychology and Curriculum Studies unit, Iringa, Tanzania \\ E-mail: mwakalolo@yahoo.ca
}

Received: Feb. 22, 2015 Accepted: March 11, 2015 Published: May 1, 2015

doi:10.5296/jse.v5i2.7146 URL: http://dx.doi.org/10.5296/jse.v5i2.7146

\begin{abstract}
Ensuring that Tanzanian secondary school students receive quality science education (SE) experiences is a desire that Tanzania has looked forward to achieving.Despite clear and well-focused intent to provide quality SE experiences in schools, the progress towards achieving a target has not been so clear over decades. This review paper analyses the SE debates and the efforts made towards achieving such a goal. The analysis in this paper is built on an attempt to trace the progress and the success of the aspiration to provide quality SE in Tanzanian secondary schools. The paper also articulates how such an expectation has been achieved so far. Eventually the paper identifies some new emphases in an effort to provide quality SE and providesa relevant approach towards achieving the goal to provide excellent SE experiences in schools.
\end{abstract}

Keywords: Quality science education, Quality, Science education 


\section{Introduction}

The provision of quality science education (SE) around the world has accelerated the pace of "science-driven change" in modern societies, allowing science as an educational subject to become more important than ever before (Lederman, 2008). Lederman (2008) argues that:

We have arrived at a point in history where there must be a major increase in the capability of ordinary people to cope with the scientific and technological culture that is shaping their lives and the lives of their children. (p. i)

With such an aspiration, improving SE has become of paramount importance in determining a country's scientific status and its socio-economic power in today's open economies. The desire to develop SE is clear, and in many countries there is an opportunity to ensure that quality, relevant and sustainable SE is provided for every student. Such attention to providing quality SE has been considered important not only to targeted scientific communities, but also to the non-scientific community (Kola, 2013).

The quest to provide quality SE in Tanzanian schools can be divided into three basic devotions, two of which have traditionally been framed as more important than the third. These devotions include: developing conceptual knowledge (content), developing procedural knowledge (how to do science), and the nature of science (learning about science). Historically, questions about the nature of science have been framed as less relevant; however, currently, and internationally, curricula are giving the nature of science a bigger focus (Bull, Gilbert, Barwick, Hipkins,\& Baker, 2010). This focus is one which is still shaping most science classrooms today.

The analysis of how Tanzania is doing with regard to how quality and relevant SE is being provided in Tanzanian secondary schools is necessary and pertinent because the issue has received limited examination in sub-Saharan African countries to date, and is consequently poorly understood in many of these countries (Ogunniyi, 1986; Organisation for Economic Co-operation and Development, 2006; Osaki, Hosea, \& Ottevanger, 2004). Of course, there have been a number of important reports related to SE in Tanzania over the past two decades, including those of Chonjo, Osaki, Possi, \& Mrutu(1996) and Osaki et al. (2004), that have strongly identified the need to improve SE in schools. Their contributions to Tanzanian science literature and their recommendations have made a major contribution towards better understanding the status of SE in the country.

The aim of this paper is to build on other previous studies by identifying the successes, failures, and the challenging situations in the process of establishingpromising SE practices and frameworks for relevant, functional and sustainable quality secondary school SE experiences among Tanzanian science learners. Identifying the progress and the gaps underlying the provision of quality SE experiences among Tanzanian secondary school learners are some of the aspects of quality education that can directly help to smoothen the transition to a high quality SE system, a system that would likely improve the students' achievements in scienceas well as enable them to play a more functional role in society (Duit \& Treagust, 2003; Goodrum, Hackling,\& Rennie, 2001). 
This paper considers the perspectives of both international and national debates regarding the appropriate approach toproviding quality SE experiences. In particular, the paper seeks to identify the progress towards providing quality SE, the challenges ahead, and the implication for appropriate SE practices.Although some studies in this paper do not necessarily come from the field of science education, they are included in this review as they explicitly explain the status of quality SE in schools, identify the gaps in provision of quality SE, and provide the appropriate direction for the provision of quality SE in schools.

\section{Conceptualizing quality education}

The concept of quality education has been given many different interpretations and meanings throughout history, yet its core meaning and purpose remains elusive and context dependent (Sifuna, 2007; Sumra \& Rajani, 2006). This is because the concept of quality education is multifaceted, with different connotations and contradictory positions (UNESCO, 2007). Tikly and Barret (2007) and Tikly (2010) attribute such illusiveness and the multifaceted nature of quality education to being grounded in the context and culture of particular settings, factors which also contribute to the uniqueness of a country's education system.

Focussing on the purposes of quality education, Houston (2008), Srikanthan and Dalrymple (2007), UNESCO (2007) and Harvey (2002) describe the concept of quality education with reference to three major measures: the acquisition of measurable knowledge, skills, and attitudes among learners; serving the economic goals of the community in which learners live; and reflecting the broader social relevance of the education provided. The last two criteria for quality education are now defined as relevance (Downes, 2005; Holt, 2000) or external quality (UNESCO, 2005).

The journey towards provision of quality education in different countries has been faced with an emergence of different frameworks that are used to describe the concept of quality education. For example, while Mosha (2000) regards quality education as a degree of goodness or excellence, Lomas (2002) regards it as a degree of fitness to what the educational beneficiary wants. Unlike UNESCO (2005), which describes the concept of quality education in terms of its ability to deliver satisfactory human fulfilment and to prepare learners to master their educational challenges and contribute to social progress and social change, others view quality education (SE in this particular case) in terms of student learning outcomes and the pedagogical characteristics (such as learner-centred, participatory, and engaging classroom features) that are associated with these outcomes (Osborne, Duschl, \& Fairbrother, 2002; Rennie \& Parker, 2000). Unlike the latter view, the studies by Holbrook (2010) and Kolsto (2001) describe the quality of education in science as a process and outcome in which there is patterned and structured thinking that is valuable, well organised, professional, proficient, helpful and useful to meet contemporary life challenges. This means that quality SE from this perspective requires more than just making multiple connections between new science ideas and old ones in the process of restructuring radical thinking.

According to Cosijn and Ingwersen (2000), Downes (2005) and Hjørland(2010), the delivery of quality education is possible only if the issues of relevance and the usability of the learning process are considered as the essential focus. This means that if the term quality is considered 
from an educational viewpoint, the quality of learning would be related to what learners have gained from school and the usefulness of what they have learnt in their educational journey (Scheerens, 2000).

\section{How has the concept of quality changed over time?}

Looking at the etymological meaning of the term quality, it is clear that the scope of quality has been changing over time (Hakielimu 2007; Harvey \& Green, 1993; Holt, 2000; Knipprath, 2010; Tikly \& Barrett, 2007). The studies by Ng (2009) and Sallis (2002) confirm that the concept of quality has gone through several waves of change. These include:

i. The focus on inspection of product or service quality (First wave of change).

ii. The shift of focus from product quality towards process quality (Second wave of change).

iii. The introduction of the concept of quality assurance, which was introduced with a focus on the quality of the organisation (Third wave of change).

iv. Shift of focus from general focus of issues to specific issues that affect everyone within an organisation (Recent wave of change).

The literature reveals that globally the education sector has also experienced a similar evolution in the definition of quality. The wave for quality education reform has mainly focused on internal effectiveness, with efforts made to improve internal school performance, particularly the methods and processes of teaching and learning in the classroom (Lomas, 2002; Manyanga, 2007). Over the last two decades the education sector has undergone another quality education reform focused on the interface effectiveness in terms of education relevance, stakeholders' satisfaction, and market competitiveness (Nikel \& Lowe, 2010).

Today the education processes and reforms, especially the SE related ones, are challenged by the constant changes in the education environment, world-wide competition, globalisation of markets, high customer demands, changing educational stakeholders, and the long-lasting impacts of information technology, global economic instability, and strong demands for economic and social development (Bull, et al. 2010). In the pursuit of new visions and aims at different levels of education, the need for life-long learning, global networking, international outlook and the use of information and technological power has arisen to ensure that the aims, content, practices and outcomes of education are relevant and functional for present and future generations (Nickel \& Lowe, 2010; UNESCO, 2005; UNICEF, 2009). The emergence of these new developments reveals a shifting focus regarding quality education.

The shift towards the provision of quality education has become an essential component of education in today's schools, because the quality education system has been identified as a central enabler for individual learners to respond appropriately to a variety of social and cultural challenges (Holt, 2000; Kubow \& Fossum, 2003). 


\section{Some new emphases towards provision of quality SE}

While being well determined to provide quality SE experiences in schools, it is important to understand that SE foci have changed in the last two decades. In this modern era of information, evidence shows that some new emphases and thoughts on quality SE have emerged. For instance, there is increasing emphasis on the 'processes' versus the 'products' of science, an emphasis on better linking science with its technological and social implications (as opposed to the current emphasis on inquiry as a predominant feature of school science), an emphasis on context, and a supportive learning environment (as opposed to established approaches to teaching that favoured universalisation of science content and pedagogy) (Bull et al., 2010). These newly emerging areas of emphasis have challenged the structure and processes of SE in today's schools.

Both UNICEF and UNESCO have recognised the new five major goals for quality education (SE in this case) which include: acquisition of survival skills; supporting the objectives of peace, citizenship and security; development of cognitive, emotional and creative capacities among learners; promoting equality; and seeking to pass global and local cultural values down to future generations (UNESCO, 2005; UNICEF, 2009). Underpinning the view by UNESCO and UNICEF is the economic, socio-cultural, political and technological developments in today's world, which are increasingly described as shaped and directed by science and by quality SE in particular (Osborne \& Dillon, 2008). This means that most socio-political, economical, scientific and technological developments in today's world depend on the quality of SE that each country is able to provide for the current and future generations of its citizens.

According to Bull et al. (2010) and Tytler (2007), the changing conditions and emphases in SE demand some modifications to how SE is planned, practised and monitored in today's schools. These changes include:

i. The changing practice of science from the traditional role of the scientist. This includes shifting from viewing science as an individually controlled pursuit to viewing it as commercial, multi-disciplinary, and technologically linked to bigger projects, which have an impact on the larger community (Goodrum, et al. 2001).

ii. The changing practice on the way the public engages with and responds to science and its products. The public has shifted from viewing science as a purely academic discipline to viewing it as a necessary undertaking for managing resources and mastering socio-economic problems (Aikenhead, 2001).

iii. The increasing attacks on science as a body of knowledge. Modern science is increasingly being attacked as being dogmatic, universalistic and for its claim as being humanity's most powerful knowledge, more 'truthful' and functional than any of the others (Symington \& Tytler, 2005). 
iv. The increasing knowledge explosion. New theories are overthrowing the old ones, new science information is being assimilated into old, unverifiable hypotheses are being discarded, hypotheses supported by evidence are being treated with greater confidence, and continuously rechecking scientific results, while tentative theories are published in scientific publications. All this must be assimilated by SE (Aikenhead, 2006; Tytler, 2007).

v. The changing nature of learning science. This is exemplified by a shifting emphasis from teacher-centred and content-centred learning to student-centred learning. This shift is promising to reduce the unnecessary difficulty of school science learning to an interesting discipline of study enjoyed by all (Fletcher, 2003).

vi. The changing audience for science education. This is marked by a shifting emphasis from science being only for a few selected people to science being open to all. Practically, this is represented by making science compulsory for all up to high school, including those not destined for post-training in SE careers. While "science for all" is still contestable, this change has led to a need for SE practices to be redefined to accommodate diverse student populations with a wide range of responses towards what is essential and worthy learning in science (Fensham, 2011).

The implication drawn from these emerging changes in SE indicates the need to readdress the way it is viewed and enacted, particularly so that it is relevant and functional for the public (Aikenhead, 2001). Achieving this goal demands a clear and focused change to the way SE is planned, practised, evaluated, and monitored. In such a process, Tytler (2007) suggests it is necessary to consider the following features of quality learning: ascertaining the sort of knowledge worth knowing and its ability to serve the future needs of students as responsible citizens; accepting that educational ends are acknowledged and adapted in informing practice; allowing a variety of voices and interests to be included when charting a way forward for relevant SE; and acknowledging the set of circumstances controlling the implementation of the whole process of providing quality SE in schools.

To deliver quality SE for a wider public, Bull, et al.(2010), Gluckman (2011), Millar and Osborne (1998), and Sjøberg and Schreiner (2010) have tried to pave the way by identifying the need for a multidimensional design of SE, which would be able to provide high standards of knowledge about science (science literacy development) alongside development of a skilled science workforce. For example, in the Tanzanian context, this could be done by introducing a compulsory general SE course for all learners at all levels of education. While part of this course would concentrate on general issues like health, the environment, and how the world around us can be used sustainably, the other part of science training could be designed for those destined for science careers.

\section{Emerging gaps in the provision of quality $\mathrm{SE}$ in Tanzania}

Despite clear and well-focused intent to strengthen the scientific knowledge base among the public, experiences reveal some limitations related to the way this is practised in Tanzanian 
schools. For example, instead of making sure that science students are provided with quality SE experiences, practices in schools still seem to be limited to the following: preparation of students for examinations at the expense of developing conceptual knowledge about science; the absence of practical work experience of some of schools in developing countries - a situation which limits the students from developing procedural knowledge in science; and the absence of clear delineation about the nature of science and its relationship with other disciplines (Hipkins et al., 2002; Tytler, 2007).

But again it appears that while the global demand for skills in a technology-based economy is increasing rapidly, little effort is being made towards improving SE in schools. In Tanzania, for example, secondary school SE, with the introduced "ward secondary schools" is facing a number of challenges related to the way science is enacted, a situation that interferes with initiatives towards developing quality SE in schools (Hakielimu, 2007; Sumra \& Rajani, 2006).

A review of some literature establishes that efforts to improve SE in most African secondary schools since the 1980s have been impacted by a number of global challenges (Ogunmade, 2005; Ogunniyi, 1986) which have greatly influenced SE practices in schools. The provision of quality SE in Tanzania seems to exhibit a similar experience coupled with several limitations including:

i) The participation gap in SE. There has been a persistent participation gap in SE among several disadvantaged groups (such as women, learners from rural areas, and learners from poor socio-economic areas) in most African countries including Tanzania (Anamuah-Mensah, Mereku, \& Asabere-Ameyaw, 2004). These groups are seriously underrepresented in many science fields, a situation which limits their potential for participating in science studies and constrains their contribution to this field.

ii) The lack of interest in science careers among many students. The desire to provide quality SE in schools has been thwarted by the loss of interest in science by many of today's youths (Munro \& Elsom, 2000). The fall in the number of secondary school leavers seeking careers in science can be demonstrated by the situation whereby many students have been turning away from science studies towards studies for other professions, thus making it difficult to find notable professionals in scientific fields, and this situation does not book well for the future of Tanzanian competence in areas of science and technology (Osaki, 2004, 2007).

iii) The poor schooling environment. This includes the lack of competent teachers who are able to inspire their students, inappropriate professional development training among teachers, as well as an absence of interesting and motivating curricula (Komba\& Nkumbi, 2008; Osaki et al., 2004). There is also a lack of clear shared standards for science and mathematics that would help all involved in the system to set and achieve goals (Reddy, 2006). As a result, too many students conclude early in their education that science subjects are too difficult, unfavourable, or boring, which leaves them inadequately prepared to face challenges in the future. 
iv) Lack of a science capable community. Despite the fact that science is important, even for people who are not planning to become engineers, mathematicians or scientists (Holbrook, 2010; Ogunmade, 2005; Osborne \& Dillon, 2008), Tanzania arguably lacks a science capable community. An increasing number of jobs today draw on at least some knowledge or skill from science fields and every occupation has the potential to be transformed by scientific and technological advances. It can be argued that it is important for Tanzanian citizens to have an understanding of scientific and technological knowledge to prepare them to make informed decisions about issues facing their nation and the planet at large.

v) Lack of a science-proficient workforce. The nation's ability to solve problems and achieve economic growth seems to largely depend on cultivating a future workforce that is science literate. This need is urgent in Tanzania because the country's economy needs an increasing supply of workers who can use scientific knowledge and skills in their jobs to fuel scientific discoveries, innovations and entrepreneurship (Osaki, et al., 2004).

vi) Lack of future science experts. Tanzania needs a steady stream of the best science researchers and innovators and a large pool of science experts with the knowledge and desire to advance science and technology in the country (Hamilton, Mahera, Mateng'e, \& Machumu, 2010). Science experts can play an important role in providing knowledge that serves a nation in various socio-economic and cultural issues such as security, mining, communication, and transportation. They can also help to develop the new ideas and inventions necessary for the country's technological development as well as inspiring and mentoring new generations of scientists, engineers and mathematicians. This group of professionals contributes immensely to economic growth, technological progress as well as developments in high-tech industries, medical research centres, and engineering firms. More importantly, they also help in retaining these advantages by building strong science expertise.

The prevalence of these challenges has altered global educational needs and thereby challenged most African schoolsincluding those in Tanzania,to transform their structures and processes of education towards more relevant issues for the learners and society at large (Levy \& Murnane, 2005; Stewart, 2010; Wilmarth, 2010). Such challenges have also led to a mismatch between the knowledge and skills that the schools offer, and the competencies that school graduates need for them to face their futures confidently.

Also the dominance of these challenges hasbeen shown to greatly impede the provision of quality SE, a criterion which is necessary for developing a strong scientific community and skilled manpower in the field (Hodson, 2011). According to Bybee (1993) and Osaki et al. (2004), the development of scientifically skilled manpower is only possible when the provision of quality and relevant SE is a central concern. This situation explains why various strategies are being put in place in developing countries to ensure their citizens are scientifically literate (World Bank, 2011).

\section{Implications of the SE changes in the Tanzanian SE practice}

It is quite evident that all nations that have attached importance to quality SE have seen how such an ambition has played a vital role in the overall development (OECD-GSF, 2006). 
Quality SE has been shown to contribute considerably to the economic development of different nations that have considered putting an emphasis on it (Bybee \& Fuchs, 2006). However, while this dream may have been realised in most western countries, it has not yet occurred in Tanzania. This situation calls for concerted efforts to develop quality SE in Tanzania, a process which is only possible when science practices and programmes are clearly redefined, legislatively protected from any political dictates, owned by relevant stakeholders, adequately financed, and constantly subjected to periodic technical consultations and reviews to ensure that they are in harmony with both local and global challenges (Nikel \& Lowe, 2010; Ogunmade, 2005).

Similarly, the close relationship between economic development and the delivery of quality SE has encouraged most developing countries to start rethinking ways they can best deliver quality SE in their schools. For example, towards its journey for such reforms, Tanzania has found itself being confronted by the challenge to produce professionals who can generate knowledge, think creatively, and solve the kinds of complex social and economic problems faced by Tanzanian communities (Hamilton et al., 2010; Mrutu, Ponera, \& Nkumbi, 2005). Tanzania has found itself faced with the challenge to address not only the needs of an increasingly complex, technologically driven economy, but also to produce professionals who can help the country caught with three development enemies, namely: ignorance, disease and poverty (URT, 1995). Another challenge is the outcry from Tanzanian education stakeholders who are demanding that SE provided in schools hasto be relevant to the Tanzanian context (Osaki et al., 2004). Responding to such demand is likely to enable the SE system to become context responsive and useful to the Tanzanians.

In the quest to achieve public scientific literacy and benefit from a well performing Tanzanian SE system, it is no longer helpful to think about quality merely in terms of maintaining standards (Stensaker, 2007). Instead, Srikanthan and Dalrymple (2003) suggest taking a developmental approach to quality as pragmatists articulate. This developmental approach would exist in the form of multi-involvement practices, whereby policy makers and planners, educators, communities, parents, teachers, students and other stakeholders in educational decisions are involved in a strategy for creating relevance, ownership and accountability for their children's education (Delputte, 2013). Such an initiative should also go in tandem with the redefinition of SE practices to make it more functional for learners and more effective in catering for their needs, especially the needs of those learners who choose to pursue the formal study of science beyond secondary education (Chonjo, et al., 1996; Osaki, et al., 2004). Another approach could involve concentrating the focus on the public outcry from parents and employers, including the private sector, who claim that there is a huge difference between the kind of graduates they expect and those being produced by schools, colleges and universities with science specialisations.

In this era of science and technology, Tanzanians will need to be knowledgeable in science to prosper in a complex and global society (Hakielimu, 2007; Mosha, 2000; TEN/MET, 2007; TEN/MET \& Oxfam, 2006). This ambition is underpinned by the belief that scientifically literate citizenry is needed to make informed decisions about their nation's health, technological developments, agricultural mechanisation, nutrition, environmental 
conservation, and food preservation which all depend upon community literacy regarding scientific principles and concepts (Knipprath, 2010; UNESCO, 2007).

The Tanzanian SE reformers are consistently calling for a more pragmatic approach towards SE reform, including a substantial change in the way SE is practised, managed, and evaluated in today's Tanzanian JSS (Osaki et al., 2004). As such, efforts towards quality SE need to be diverted to focus on identifying the vital capacities learners need if they are to become well-functioning members of society amid the uncertain terrain of the twenty first century (Bybee, 2006; Osaki et al., 2004). In the process of making sure that quality SE experiences are provided in schools, several questions are important to answer: What type of knowledge is worth knowing? What type of people does Tanzania want to produce? How can SE be organised to address the current and future challenges of life? These questions reveal a widespread concern about the relevance and outcomes of SE in schools (Bull et al., 2010; Hamilton et al., 2010; Stronkhorst, 2001).

Similarly, the studies by Bolstad (2011) and Gluckman (2011) argue for the necessity to have SE visions focused on the students' sense of identity, self-reliance, effective and creative thinking, team work skills, and the affective aspects of student learning as determined by engagement in on-going learning. This view is advanced in reports by Chonjo et al. (1996), Millar \& Osborne (1998), and Tytler (2007), all of whom reveal some attempts to refocus SE by developing students' capacities to solve their contextual challenges through the application of learnt science knowledge.

\section{Promising new framework for addressing quality SE in Tanzania}

As modern civilization has developed, there is a need for improving the quality and relevance of science education in every country in the world (Osborne \& Dillon, 2008). In the Tanzanian context there have been a variety of projects initiated to improve the quality of SE, all of which have focused on improving the way SE is enacted in schools (Chonjo et al., 1996; Osaki et al., 2004). In many situations, however, these projects were limited by scope and duration, were teacher-centred rather than learner-centred, and (as the next chapter addresses more fully) came from a western guided perspective. As a result, these projects have not impacted positively on students' learning experiences (Osaki, 2004, 2007).

It is also evident that while Tanzanian researchers' efforts to improve SE have produced little impact, the government can also be blamed for assigning limited amounts of resources to SE, practices which together have ultimately led to the weak scientific and technological foundations of SE in the country (Hamilton et al., 2010). It is perhaps surprising that in this global era, where SE holds the first priority in socio-economic development, Tanzania still embraces weak SE frameworks which have failed to capture students' interests in SE, and to sustain their desires to learn science throughout their lives (URT, 2007).

Unlike the poor trend of SE in Tanzania, evidence also shows that there has been growing demand for the public to engage with science and applications of science in the form of rapidly developing technologies such as computers and mobile phones (Hamilton et al., 2010; Hjørland, 2010; Schreiner \& Sjoberg, 2004). However, SE practices in schools are still 
focused on the preparation of students who know and "can consume" large amounts of scientific information, but are unable to develop the creative and innovative skills necessary for their survival; nor are they able to use the learnt knowledge to address and possibly solve science related social issues (Andres \& Mattias, 2006; Osaki et al.,2004). Tanzanian SE is also blamed for its failure to develop individual learners into sound, effective citizens and self-dependent individuals who are able to respond to the contextual pressures and overcome the existing challenges (Osaki \& Njabili, 2003; URT, 1995). The picture gained from identifying these challenges suggests that these crises cannot be solved by using a straightforward puzzle-solving methodology. Rather, a diverse and pluralistic approach is needed to redefine the ways in which SE is enacted in schools, which in turn will make Tanzanian SE more functional for society at large (Lyons, 2004; Osborne \& Dillon, 2008).

It is in the view of this paper that there is a need to have a new approach towards successful provision of quality SE in Tanzanian JSS. This desire, however, requires a transparent, participatory negotiation process towards meeting stakeholders' needs and expectations in SE. This review takes into consideration the importance of differing perspectives among SE stakeholders, because each is able to present their specific understanding of what constitutes quality SE. This consideration is based on a belief that finding a consensus from different perspectives might help in solving the etymological complexity of defining the concept of quality SE (Tikly, 2010).

The author also considers the concepts of relevance, functionality and context responsiveness as central aspects to be used in judging the quality of SE in a Tanzanian context. This standpoint comes with an assumption that the quality of any educational process can only be understood from the particular standpoint of a specific category of stakeholders, culture, or context and the conviction of what the beneficiaries believe to be worth achieving in SE (Nikel \& Lowe, 2010; UNESCO, 2007).

Being more precise, this review considers the importance of adapting some ideas from O'Sullivan's (2006) approach which defines quality education with contextual and multidimensional perspectives. This approach is important in the Tanzanian context because it locates the phenomenon as a multifaceted and context dependent concept, which can only be assessed clearly from the particular standpoint of a specific category of stakeholder. This approach also recognises the Communiqué of the 2003 Ministerial Round Table on Quality Education which emphasised the need to take into account the multiple perceptions of different stakeholders when aiming to reach a consensus on the desired SE outcomes and best ways to achieve them. Given such an ambition, engaging various key players in SE by building a consensus that best responds to the diverse interests of the multiple stakeholders in Tanzanian JSS science education is commendable.

\section{Conclusion}

Quality SE is identified in this paper as one of the important basic prerequisites for individual learners to respond appropriately to a variety of social and cultural contexts. With such a remarkable role of SE in individual functionality, it is deemed important to provide quality SE experiences if a country is to remain globally competitive. This need places pressure on 
Tanzania to reform the SE system. In the context of this review, such reform could involve an intensive inquiry about the relevance, context responsiveness, functionality and applicability of the present SE practices to the Tanzanian learners. The answers to these queries are likely to have an impact on the following: the philosophy of education in Tanzania, educational policies in practice, the SE curriculum in use, teachers' pedagogical practices, and the assessment procedures.

The need to undertake multi-sourced intervention and substantial changes to Tanzanian SE is also becoming stronger because most of the SE practices in the Tanzanian education system have roots in colonialism, whose aim was to herald and perpetuate the western culture in education. These practices have in turn led to a disconnection between classroom SE experiences and the real life experiences of learners. To solve such disconnection requires a shift in approaches from the colonial-based educational approaches which celebrate fixed, faulty, narrow confines, absolutism and conservative modes of looking at education to pragmatically based approaches that accommodate the aspects of relevance, functionality and context responsiveness education.

While acknowledging the contributions made by other studies, this paperhas contributed the followingto the SE debates:

- It has identified the need to consider the illusiveness of the concept of quality as defined by different people and influenced by different contexts.

- It has provided evidence about the current status of SE in Tanzanian JSS and the need to develop functional, relevant, and context responsive SE.

- It has shown how different SE stakeholders understand and describe quality SE, information that can be useful to policy makers and other SE stakeholders in making informed decisions about improving quality SE in JSS.

- It has highlighted the complex issues that are likely to define both the present and future SE practices, information which may be useful in developing informed decisions on how to overcome the present challenges in SE.

- It has contributed to the definition of a systematic and sustainable framework for quality

SE in Tanzanian secondary schools which could guide the debate around reforms in SE through evidence.

Otherwise It should be noted that developing a quality SE system may be difficult at times, but should any attempt be made, the reflection should be based on the criteria related to the ability of the education system to serve local community needs (relevance), and criteria addressed to meeting both global and contextual demands, all of which need to be tied to a specific country's own history and culture.

It is generally anticipated that the contribution of this review to the SE discourses, theory and future studies will likely help to accelerate the efforts to improve quality SE in Tanzanian JSS. 
It is also hoped that through this review SE in the near future will be collectively influenced, relevant to the learners, responsive to both contextual and global demands, functional, and applicable to the Tanzanian learners.

\section{References}

Aikenhead, G. S. (2001). Students' ease in crossing cultural borders into school Science, Science Education, $\quad 85, \quad 180-188$. http://dx.doi.org/10.1002/1098-237X(200103)85:2<180::AID-SCE50>3.0.CO;2-1

Aikenhead, G.S. (2006). Science education for everyday life: Evidence-based practice. New York: Teachers College Press.

Anamuah-Mensah, J., Mereku, D. K., \& Asabere-Ameyaw, A. (2004). Ghanaian junior secondary school students' achievement in mathematics and science: Results from Ghana's participation in the 2003 Trends in International Mathematics and Science Study, Accra: Ministry of Education Youth and Sports.

Andres, A., \& Mattias, N. (2006).Tanzania education sector policy overview paper. Dar es Salaam. Tanzania.

Bolstad, R. (2011). Taking a "future focus" in education: What does it mean? An NZCER working paper from the Future-Focussed Issues in Education (FFI) project. Wellington: New Zealand Council for Educational Research.

Bull, A., Gilbert, J., Barwick, H., Hipkins, R., \& Baker, R. (2010). Inspired science: A paper commissioned by the Royal Society and the Prime Minister's Chief Science Advisor. New Zealand Council for Educational Research.

Bybee, R. W. (1993). Reforming science education: Social perspectives and personal reflections. New York: Teachers' College Press.

Bybee, R.W. (2006). Science teaching in the $21^{\text {st }}$ century: Five themes for educational leaders. Dubuque, IA: Kendall/Hunt Publishing Company.

Bybee, R.W., \& Fuchs, B. (2006). Preparing the 21st century workforce: A newreform in science and technology education. Journal of Research in Science Teaching, 43(4), 349-52. http://dx.doi.org/10.1002/tea.20147

Chonjo, P. N., Osaki, K. M., Possi, M., \& Mrutu, S. (1996). Improving science education in secondary schools: A situational analysis of selected government secondary schools in Tanzania mainland. Dar es Salaam, Tanzania: Ministry of Education and Culture.

Cosijn, E., \& Ingwersen, P. (2000).Dimensions of relevance. Information Processing \& Management, 36(4), 533-550. http://dx.doi.org/10.1016/S0306-4573(99)00072-2

Delputte, S. (2013). The EU as an emerging coordinator in development cooperation: Perspectives from sub-Saharan Africa1. AFRIKA FOCUS,26(1), 99-107. 
Downes, S. (2005). Some principles of effective e-learning, Canada, National Research Council. Retrieved on February $20^{\text {th }}$, 2011 from http://www.downes.ca/cgl/website/page.cgi?db.

Duit, R., \& Treagust, D. F. (2003). Conceptual change: A powerful framework for improving science teaching and learning. International Journal of Science Education, 25(6), 671-688. http://dx.doi.org/10.1080/09500690305016

Fensham, P. J. (2011). Globalization of science education: Comment and a commentary. Journal of Research in Science Teaching, 48(6), 698-709. http://dx.doi.org/10.1002/tea.20426

Fletcher, A. (2003). Meaningful Student Involvement: Guide to Inclusive School Change. Olympia, WA: The Freechild Project.

Gluckman, P. (2011). Looking ahead: Science education for the twenty-first century. A paper commissioned by the Royal Society and the Prime Minister's Chief Science Advisor. Wellington, New Zealand Council for Educational Research.

Goodrum, D., Hackling, M., \& Rennie, L. (2001).The status and quality of teaching and learning of science in Australian schools: A research report. Canberra: Department of Education, Training and Youth Affairs.

Hakielimu. (2007). Redefine quality education in Tanzania: From input to capabilities. Working paper, October, 2007. Dar es salaam.

Hamilton, M., Mahera, W. C., Mateng'e, M. F. J., \& Machumu, M. M. (2010). A needs assessment study of Tanzania science education in Tanzania: Dar es Salaam. The Economic and Social Research Foundation (ESRF).

Harvey, L. (2002). Evaluation for what? Teaching in Higher Education, 7(3), 245-264. http://dx.doi.org/10.1080/13562510220144761

Hipkins, R., Bolstad, R., Jones, A., Barker, M., Bell, B., Coll, R., \& Haigh, M.J. (2002). Curriculum, learning and effective pedagogy: A literature review in science education. Wellington: Ministry of Education.

Hjørland, B. (2010). The foundation of the concept of relevance. Journal of the American Society for Information Science and Technology, 61 (2), 217-237.

Hodson, D. (2011). Looking to the future: Building a curriculum for social activism. Rotterdam.The Netherlands: Sense. http://dx.doi.org/10.1007/978-94-6091-472-0

Holbrook, J. (2010). Education through science as a motivational innovation for education for all. Science Education International, 21(2), 80-91.

Holt, M. (2000). Introduction: The concept of quality in education, in improvingquality in education. in C. Hoy, C. Bayne-Jardine, \&M. Wood,(eds),London Falmer.

Houston, D. J. (2008). Rethinking quality and improvement in higher education. Quality Assurance in Education, 16 (1), 61-79. http://dx.doi.org/10.1108/09684880810848413 
http://www.nuffieldfoundation.org/fileLibrary/pdf/Sci_Ed_in_Europe_Report_Final.pdf on $1^{\text {st }}$ March. 2011.

Knipprath, H. (2010). What PISA tells us about quality and inequality of Japanese education in mathematics and science. International Journal of Science and Mathematics Education, 9, 389-408. http://dx.doi.org/10.1007/s10763-010-9196-5

Kola, A. J (2013). Importance of science education to national development and problems militating against its development. American Journal of Educational Research, 1(7), 225-229. http://dx.doi.org/10.12691/education-1-7-2

Kolsto, S. D. (2001). Scientific literacy for citizenship: Tools for dealing with the science dimension of controversial socio scientific issues. Science Education, 85, 291-310. http://dx.doi.org/10.1002/sce.1011

Komba, W., \& Nkumbi, E. (2008). Teacher professional development in Tanzania: Perceptions and Practices. Journal of International Cooperation in Education, 11(3), 67-83.

Kubow, P. K., \&Fossum, P. R. (2003). Comparative education: Exploring issues in international context. Upper Saddle River NJ: Merrill Prentice Hall.

Lederman, L. (2008). Science education and the future of humankind. ScienceNews, 173(16), 1 .

Levy, F., \& Murnane, R. J. (2005). The new division of labour: How computers are creating the next job market. Princeton, NJ: Princeton University Press.

Lomas, L. (2002). Does the development of mass education necessary mean the end of quality? Quality in Higher Education, 8(1), $71 \quad$ - 79. http://dx.doi.org/10.1080/13538320220127461

Lyons, T. (2004).Choosing physical science courses: The importance of cultural and social capital in the enrolment decisions of high achieving students. Paper presented at the 11th Symposium of the International Organisation for Science and Technology Education (IOSTE), Lublin, Poland.

Manyanga, T. (2007). Standards for quality in tertiary education: The case ofTanzania. Quality Assurance in Education, 16(2), 164-180.

Millar, R., \& Osborne, J. (1998). Beyond 2000: Science Education for the future. The report of a seminar series funded by the Nuffield Foundation. London: King's College London, School of Education.

Mosha, H. J. (2000). Conceptualizing quality education. In J.C.J. Galabawa,F.M.K. Senkoro and A.F. Lwaitama (eds.),The quality of education inTanzania: Issues and experiences. Faculty of Education, University ofDar es Salaam.

Mrutu, A., Ponera, G., \& Nkumbi, E. (2005).The SACMEC II Project in Tanzania: A study of the conditions of schooling and the quality of education (pp.198-201). Harare: SACMEQ. 
Munro, M., \& Elsom, D. (2000). Choosing science at 16. NICEC project report, Cambridge: NICEC

Ng, P.T. (2009). Relating quality and innovation: An exploration. International Journal of Quality and Innovation, 1, 3-15. http://dx.doi.org/10.1504/IJQI.2009.026460

Nikel, J., \& Lowe, J. (2010). Talking of fabric: a multi-dimensional model of quality in Education. Compare: A Journal of Comparative and International Education, 40(5), 589-605.

Ogunmade, O.T. (2005). The status and quality of secondary science teaching and learning in Lagos State Nigeria,(PhD Thesis). Edith Cowan University, Perth Australia. http://dx.doi.org/10.1002/sce.3730700205

Ogunniyi, M. B. (1986). Two decades of science education in Africa. Science Education, 70 (2), 111-122

Organisation for Economic Co-operation and Development -Global Science Forum-OECD-GSF. (2006). Evolution of student interest in science and technology studies policy report. Paris: OECD

Osaki, K., \& Njabili, A. (2003). Secondary education sector analysis. Report to the Ministry of Education and Culture and World Bank. Tanzania: Dar es Salaam.

Osaki, K., Hosea, K., \& Ottevanger, W. (Eds.) (2004). Reforming science and mathematics education in sub-Saharan Africa: Obstacles and opportunities. Dar es Salaam: TEAMS, University of Dar es Salaam.

Osaki, K.M. (2004). Reflections on the state of science education in Tanzania. In Osaki K.M. Hosea, K, Ogevanger, W.J.W (eds). Reforming science and mathematics education in sub Saharan Africa: Obstacles, opportunities. Dar es Salaam \& Euschede: TEAMS Project.

Osaki, K.M. (2007). The challenge of science and mathematics education in Tanzania. Paper Presented at the Workshop to Launch the National Science INSET Programme. Dar es Salaam: Ministry of Education and Vocational Training.

Osborne, J., \& Dillon, J. (2008).Science education in Europe: Critical reflections. A Report to the Nuffield Foundation. Retrived from,

Osborne, J., Duschl, R., \& Fairbrother, B. (2002). Breaking the mould? Teaching science for public understanding. London: School of Education, King's College.

O'Sullivan, M. (2006). Lesson observation and quality in primary education as contextual teaching and learning processes. International Journal of Educational Devleopment, 26, 246-260. http://dx.doi.org/10.1016/j.ijedudev.2005.07.016

Reddy, V. (2006). Challenges to meet international maths and science standards, HSRC Review, 4(1). 
Rennie, L. J., \& Parker, L. H. (2000).Toward quality in assessment practice in schools. Paper presented at the annual meeting of the American Educational Research Association, New Orleans, LA.

Sallis, E. (2002). Total quality management in education. London: Psychology Press.

Scheerens, J. (2000). Improving school effectiveness.Fundamentals of Educational Planning, $68,18-31$.

Schreiner, C., \& Sjoberg, S. (2004). Rose - The Relevance of Science Education. (4). Oslo: ILS.

Sifuna, D. (2007). The challenges of increasing access and improving quality: An analysis of Universal Primary Education intervention in Kenya and Tanzania since 1970s. International Review of Education, 53, 687- 699. http://dx.doi.org/10.1007/s11159-007-9062-z

Sjøberg, S., \& Schreiner, C. (2010). The relevance of science education (ROSE) Project: An overview and key findings. Norway: University of Oslo. http://folk.uio.no/sveinsj/ROSE-overview_Sjoberg_Schreiner_2010.pdf.

Srikanthan, G., \& Dalrymple, J. (2003). Developing alternative perspectives for quality in higher education. The International Journal of Educational Management, 17(3), 126-36. http://dx.doi.org/10.1108/09513540310467804

Stensaker, B. (2007). Impact of quality processes. Embedding quality culture in higher education: Selection of papers from the 1st European forum for quality assurance 2007. $\begin{array}{llll}\text { Retrieved } & \text { onNovember } & 22, & \text { from }\end{array}$ www.eua.be/fileadmin/user_upload/files/Publications/EUA_QA_Forum_publication.pdf)

Stewart, V. (2010).A classroom as wide as the world. In H. Hayes Jacobs (ed.), Curriculum 21: Essential education for a changing world, (pp.97-114). Alexandria, VA: Association for Supervision and Curriculum Development.

Stronkhorst, R. (2001). Improving science education in Swaziland. Doctoral dissertation. Enschede: University of Twente,

Sumra, S., \& Rajani, R. (2006). Secondary education in Tanzania: Key policy Challenges. Working paper on the Norwegian Post- Primary Education Fund for East Africa (NPEF),Dar es Salaam:HakiElimu

Symington, D., \& Tytler, R. (2005). Designs on science: Intelligent design merits intelligent debate in schools. Australian (Canberra, A.C.T.). Nationwide News Pty Limited, Canberra, A.C.T.

TEN/MET. (2007). Report on Critical issues and challenges in secondary education in Tanzania. Study conducted by the Bureau of Education Research and Evaluation. Faculty of Education. University of Dar es Salaam.

TEN/MET., \& Oxfam. (2006). Quality Education Conference Kunduchi Declaration. Dar es Salaam: TEN/MET/Oxfam. 


\section{Macrothink}

Journal of Studies in Education

ISSN 2162-6952

2015, Vol. 5, No. 2

Tikly, L. (2010). A roadblock to social justice? An analysis and critique of the South African education Roadmap. International Journal of Educational Development, 31(1), 86-94. http://dx.doi.org/10.1016/j.ijedudev.2010.06.008

Tikly, L.,\& Barrett, A.M. (2007). Education quality. Research priorities and approaches in the global era. Bristol: University of Bristol.

Tytler, R. (2007). Re-imagining science education: Engaging students in science for Australia's future. Camberwell Vic: Australian Council for Educational.

UNESCO. (2005). EFA global monitoring report 2005: Education for All, the quality imperative. Paris: Author

UNESCO. (2007). Quality education for all: A human rights' issue. Background document for the Second Meeting of the Intergovernmental Committee of the Regional education Project for Latin America and the Caribbean-PRELAC.Santiago: Author

UNICEF. (2009). Child friendly schools. New York: UNICEF.

United Republic of Tanzania (URT). (1995). Education and training policy. Dar Es Salaam: Ministry of Education Culture.

URT. (2007). The Tanzania national ICT policy for basic education. Dar e Salaam United Republic of Tanzania.

Wilmarth, S. (2010). Five socio-technology trends that change everything in learning and teaching. In Heidi Hayes Jacobs (ed.), Curriculum 21: Essential education for a changing world, (pp.80-96). Alexandria, VA: Association for Supervision and Curriculum Development.

World Bank. (2011). A regional exploration of pathways toward harmonization of math and science curriculum in the East African Community. Discussion Paper. African region: Author.

\section{Copyright Disclaimer}

Copyright for this article is retained by the author(s), with first publication rights granted to the journal. This is an open-access article distributed under the terms and conditions of the Creative Commons Attribution license (http://creativecommons.org/licenses/by/3.0/). 